\title{
OPTIMIZATION OF MODES OF SUBMERGED ARC SURFACING OVER THE LAYER OF ALLOYING CHARGE OF CATERPILLAR MACHINE RUNNING GEAR PARTS
}

\author{
V.V. PEREMITKO and D.G. NOSOV \\ Dneprodzerzhinsk State Technical University \\ 2 Dneprostroevskaya Str., 51918, Dneprodzerzhinsk, Ukraine. E-mail: science@dstu.dp.ua
}

\begin{abstract}
The optimization of modes of submerged arc surfacing with application of external magnetic field over the layer of alloying charge of caterpillar machine running gear parts was carried out. The influence of external axial magnetic field parameters and powders of silicon carbide $\mathrm{SiC}$ and aerosil $\mathrm{SiO}_{2}$, introduced with the charge, on hardness and microhardness of the deposited metal was studied. During experiments the concentration of silicon compounds in alloying charge, number of deposited layers, deviation in the arrangement of the latter relatively to the arc axis as well as induction of the external magnetic field were changed. The regression dependence of hardness on surfacing mode parameters for two types of charge is presented. The software complex was designed intended to determine the parameters of arc surfacing mode according to the proposed scheme to provide the maximum effect of using external influences. 11 Ref., 1 Table, 3 Figures.
\end{abstract}

$\boldsymbol{K} \boldsymbol{e} \boldsymbol{y} \boldsymbol{w} \boldsymbol{o r d} \boldsymbol{s}:$ arc surfacing, alloying charge, external magnetic field, powders $\mathrm{SiC}$ and $\mathrm{SiO}_{2}$, regression dependences, designing of surfacing technology

Analysis of organization and carrying out of surfacing works shows that for restoration of parts, which at first sight operate approximately under the same conditions, a rather wide range of surfacing materials is commonly proposed differing by degree, and sometimes by alloying system which is not always justified [1-4]. In particular, it is well known from the experience of restoration of running gear parts of caterpillar machines that the requirements to deposited metal depending on conditions of the further operation (operation mode, hardness and granulometric composition of abrasive particles getting to the pairs of friction, etc.) can vary considerably [5].

As a result, for surfacing of the same running gear parts of caterpillar machines (conveyor rollers, rollers, tracks) it becomes necessary to use surfacing materials differing, in the first turn, by hardness, chemical composition and structure. It was established [6] that depending on the mentioned operation conditions the hardness of metal deposited on running gear parts of caterpillar machines should vary in the range of $H V$ 285-435 (HB 283-413), which almost can not be achieved using only one grade of surfacing wire.

It has been shown [7] that changing of hardness of deposited metal in a rather wide range is possible in arc surfacing over the layer of alloying charge previously clad on the surface to be deposited. However, this method has a significant dis-

(C) V.V. PEREMITKO and D.G. NOSOV, 2015 advantage, i.e. during its use the specified composition and good formation of deposited metal can be achieved only in a narrow range of surfacing modes [1]. Improving these parameters is possible due to application of external magnetic field, which, according to some information, has a positive influence on formation of deposited beads and properties of the deposited layers [8, 9].

The aim of these investigations was in optimization of modes of submerged arc surfacing with application of external magnetic field over the layer of alloying charge of running gear parts of caterpillar machines providing a specified hardness of the deposited layer.

To achieve this aim, the experiments on arc surfacing over the layer of alloying charge deposited on the surface of specimens of steel St3 with hardness HB 197-207 were conducted. During surfacing the external axial magnetic field was imposed on welding arc, thus increasing the width of weld pool. This allowed applying filler charge with displacement from the axis of the arc and made it possible to control the process of its melting. As the filler charge the powders of silicon carbides $(\mathrm{SiC})$ and aerosil $\left(\mathrm{SiO}_{2}\right)$ were used mixed with iron powders and binding substances.

Surfacing of specimens was performed using wire $\mathrm{Sv}-08 \mathrm{~A}$ of $3 \mathrm{~mm}$ diameter under flux AN348A in installation UD-209. The surfacing conditions are the following: current $400 \mathrm{~A}$, voltage 32-36 V, wire feed rate $160 \mathrm{~m} / \mathrm{h}$, deposition rate $12-16 \mathrm{~m} / \mathrm{h}$, step of surfacing $6-8 \mathrm{~mm}$, electrode stick-out $30 \mathrm{~mm}$, current was direct, polarity - reversed. The coil, providing axial mag- 
Proportions of mixtures and their consumption per unit of a weld length

\begin{tabular}{||l|c|c||}
\hline \multicolumn{1}{|c|}{ Scheme of layers deposition } & \multicolumn{2}{c||}{ Hardness $H B$} \\
\cline { 2 - 4 } & Deposited layer & HAZ \\
\hline Without additional effects & 243 & 220 \\
\hline With imposition of constant magnetic field, $B_{z}=20 \mathrm{mT}$ & 248 & 229 \\
\hline With imposition of alternating magnetic field, $f=50 \mathrm{~Hz}, B_{z}=20 \mathrm{mT}$ & 277 & 239 \\
\hline With imposition of alternating magnetic field, surfacing along the charge with $\mathrm{SiC}_{2}$ powder & 452 & 227 \\
\hline With imposition of alternating magnetic field, surfacing along the charge with $\mathrm{SiO}_{2}$ powder & 512 & 245 \\
\hline
\end{tabular}

netic field, was attached to the torch so that the nozzle and electrode wire passing through it could serve as an additional ferromagnetic core. The coil was supplied with alternating or direct current. During experiments, the filler charge layers were placed at different distance from the axis of electrode wire, and their width was in the range of $8-10 \mathrm{~mm}$.

To reduce the number of experiments a central planning of decomposition of the second order for the four factors (mixture composition; number of deposited layers of the mixture; eccentricity in the arrangement of alloying charge layer relatively to the axis of electrode wire; induction of external magnetic field) was performed. The experimental data processing was carried out with mathematical package STATISTICA 6.0.

To measure hardness on device TK-2, the plane specimens of $15 \mathrm{~mm}$ thickness were cut out of the deposited plates. The results of hardness measurement show that the effectiveness of supplying alternating magnetic field to the coil is higher than that of the constant one (see the Table).

The regression equation of hardness of deposited metal has the following form:

$$
\begin{gathered}
H B=-19.8459-894.036 A-90.713 N+ \\
+354.479 n+162.6051 B+695.3873 A^{2}- \\
-110.68 N^{2}-975.169 n^{2}-1.08627 B^{2}- \\
-17.2259 A N+286.0339 A n+3.448646 A B+ \\
+958.2996 N n+10.45245 N B-63.9323 n B,
\end{gathered}
$$

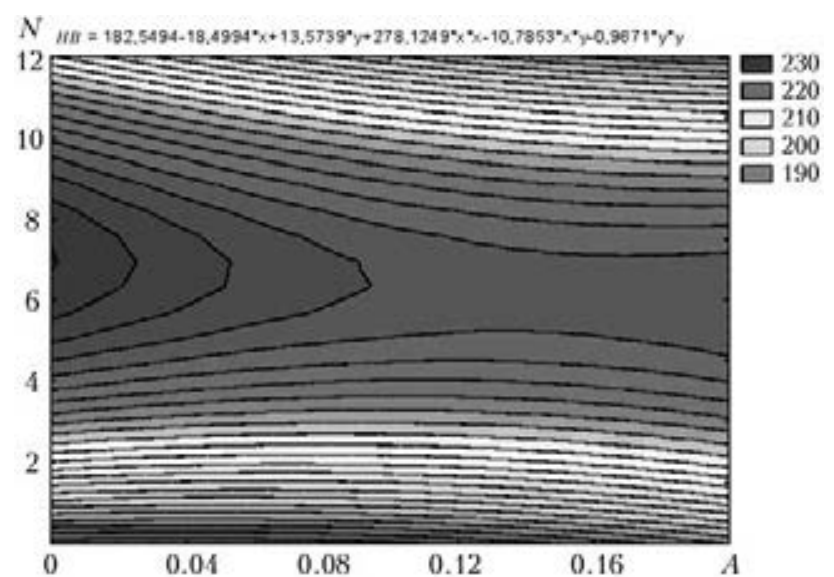

Figure 1. Dependence of hardness $H B$ of deposited metal on distance $N$ between the axis of electrode and layer of charge and concentration $A$ (mass share) of aerosil $\mathrm{SiO}_{2}$ in charge where $N$ is the distance from the axis of electrode to the layer of charge, $\mathrm{mm} ; A$ is the concentration (mass share) of $\mathrm{SiC}$ (up to 0.15 ) or $\mathrm{SiO}_{2}$ (over 0.15 ) in charge; $n$ is the number of layers; $B$ is the magnetic field induction, $\mathrm{mT}$.

As it follows from the obtained data (Figure 1), the optimal is the arrangement of charge layer at 4-10 $\mathrm{mm}$ distance from the axis to the electrode. If the layer is located closer then it melts completely together with refractory particles, if it locates farther, it falls outside the melting zone.

With increase in external magnetic field induction the width of weld pool increases causing a complete remelting of charge and, as a result, a complete melting of dispersed material. As a result, a decrease in hardness (Figure 2, zone $B=$ $=60-80 \mathrm{mTl}$ ) is observed.

To determine the optimum parameters of arc surfacing mode with simultaneous application of external magnetic field providing a maximum benefit from dispersed material introduced in arc surfacing, a software complex was designed ( $\mathrm{Fi}-$ gure 3).

The parameters of surfacing mode, at which the desired hardness of deposited layer is achieved, are determined in the following sequence.

Stage 1 . The user enters the value of necessary hardness $H B$ of deposited layer.

Stage 2. The diameter of electrode wire $d_{\mathrm{e}}$ $(\mathrm{mm})$ is specified and either self entering of basic surfacing modes (current $I_{\mathrm{S}}(\mathrm{A})$, deposition rate

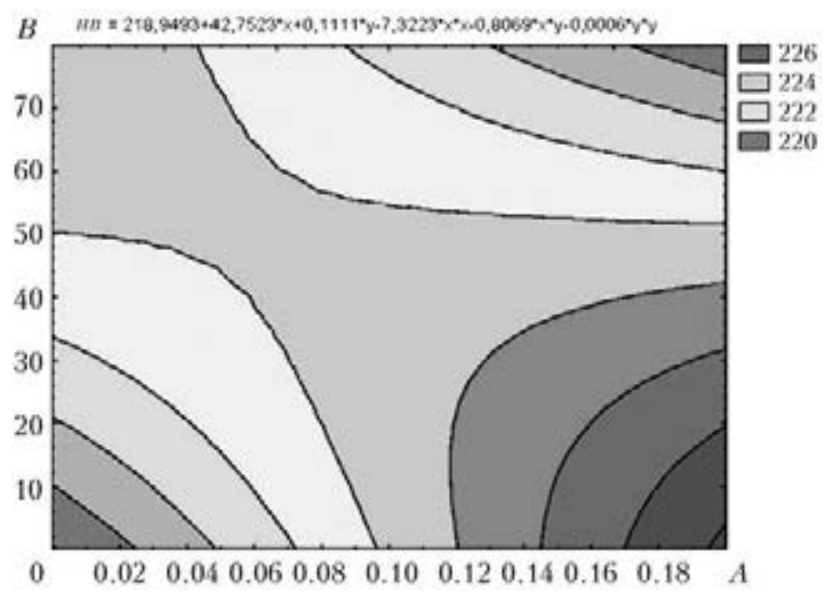

Figure 2. Dependence of hardness $H B$ of deposited metal on magnetic induction $B(\mathrm{mT})$ of external axial field and concentration $A$ (mass share) of aerosil $\mathrm{SiO}_{2}$ in charge 


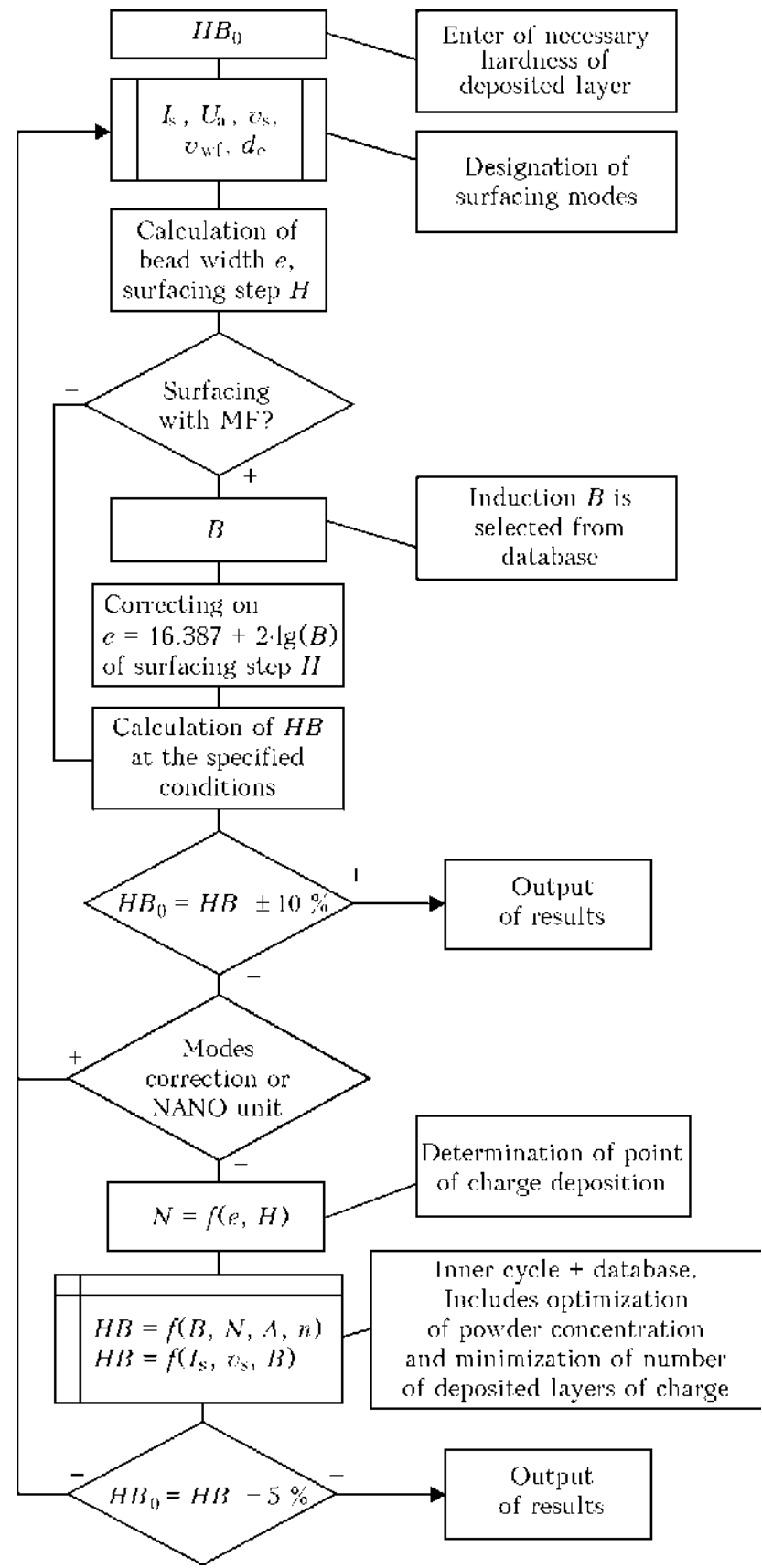

Figure 3. Algorithm for determination of optimum parameters of surfacing mode

$v_{\mathrm{S}}$ and wire feed rate $\left.v_{\mathrm{wf}}(\mathrm{m} / \mathrm{h})\right)$ from the software database or manual entering of the specified modes are offered. The user specifies conditions for the further calculation of surfacing parameters: with use of additional magnetic field (MF) or without it.

Stage 3. Calculation of the width of single deposited bead $e(\mathrm{~mm})$, which is formed under the conditions of surfacing at specified modes and surfacing step $H$. If the surfacing mode with MF was selected, then the program selects MF induction values from the database, correction of width and step of surfacing is performed.

Stage 4. Calculation of hardness of the deposited layer $H B$ in surfacing without use of charge.
Stage 5. Determination of coordinates of charge layer arrangement as function $N=f(e, H)$.

Stage 6. Determination of hardness of deposited metal using available database. It includes optimization of concentration of powder material and minimization of number of deposited layers of charge.

Complex data processing with application of algorithms and models, published in [10,11], is performed.

As the practice of using the program shows, in case of applying automatic correction of surfacing modes, return to the initial unit in manual mode in $95 \%$ of cases is not required.

\section{Conclusions}

1. It was determined that use of alternating magnetic field, imposed on welding arc, causes a greater increase in hardness of the deposited metal than use of constant magnetic field.

2. Analytical dependence for determination of hardness of the deposited layers is offered, which is achieved by additional supply of alloying charge with carbides or oxides of silicon and imposition of external magnetic field.

3. Software complex was developed intended to determine the parameters of arc surfacing providing maximum benefit from the introduced dispersed material and imposition of external magnetic field.

1. Frumin, I.I. (1961) Automatic electric arc surfacing. Kharkov: Metallurgizdat.

2. Livshits, L.S., Grinberg, N.A., Kurkumelli, E.G. (1969) Principles of alloying of deposited metal. Moscow: Mashinostroenie.

3. Khrushchev, M.M., Babichev, M.A., Berkovich, E.S. et al. (1971) Wear resistance and structure of hard deposits. Moscow: Mashinostroenie.

4. Ryabtsev, I.A. (2004) Surfacing of machine and mechanism parts. Kiev: Ekotekhnologiya.

5. Peremitko, V.V., Kuznetsov, V.D. (2014) Account of abrasive granulometric composition in repair surfacing of running gear parts of caterpillar machines. Problemy Tertya ta Znoshuvannya, 64(3), 125-130.

6. Peremitko, V.V., Cherednik, E.A. (2010) Adaptation technology of repair of running gear parts of road machines. Svarshchik, 4, 16-17.

7. Peremitko, V.V. (2014) Wear-resistant arc surfacing over the layer of alloying charge. The Paton Welding J., 8, 54-57.

8. Razmyshlyaev, A.D., Mironova, M.V. (2009) Magnetic control of bead and weld formation in arc surfacing and welding. Mariuopol: PriazovGTU.

9. Ryzhov, R.M., Kuznetsov, V.D. (2010) Magnetic control of welded joint quality. Kiev: Ekotekhnologiya.

10. Nosov, D.G., Peremitko, V.V. (2009) Algorithm of optimization of technological parameters in surfacing of parts of «shaft» type and its realization. Matemat. modelyuv., 20(1), 33-36.

11. Peremitko, V.V., Rejderman, Yu.I., Cherednik, E.A. (2006) Procedure of calculation of optimal surfacing modes. In: Proc. of 10th Interstate Sci.-Method. Conf. on Problems of Mathematical Modeling (DniprodzerzhinskDTU), 84-85. 